NATIONAL LABORATORY

\title{
METHODS FOR VERIFICATION OF THE HYDROGEN AND BORON CONTENT OF THE RCSB FOR STORAGE OF HEU AT THE HEUMF
}

\author{
J. T. Mihalczo \\ J. S. Neal
}

November 2002 


\section{DISCLAIMER}

This report was prepared as an account of work sponsored by an agency of the United States government. Neither the United States Government nor any agency thereof, nor any of their employees, makes any warranty, express or implied, or assumes any legal liability or responsibility for the accuracy, completeness, or usefulness of any information, apparatus, product, or process disclosed, or represents that its use would not infringe privately owned rights. Reference herein to any specific commercial product, process, or service by trade name, trademark, manufacturer, or otherwise, does not necessarily constitute or imply its endorsement, recommendation, or favoring by the United States Government or any agency thereof. The views and opinions of authors expressed herein do not necessarily state or reflect those of the United States Government or any agency thereof. 
ORNL/TM-2002/253

\title{
METHODS FOR VERIFICATION OF THE HYDROGEN AND BORON CONTENT OF THE RCSB FOR STORAGE OF HEU AT THE HEUMF*
}

\author{
John T. Mihalczo and John S. Neal
}

\section{EXECUTIVE SUMMARY}

Extensive measurements at the Oak Ridge National Laboratory (ORNL) with BoroBond ${ }^{\mathrm{TM}}$ blocks of varying thickness, natural boron carbide $\left(\mathrm{B}_{4} \mathrm{C}\right)$ content, and water content, and with a simplified mockup of the Rackable Can Storage Box (RCSB) of fixed natural $\mathrm{B}_{4} \mathrm{C}$ and water content, have led to a method of quantifying the water content of RCSBs by fast neutron time-of-flight transmission measurements (NMIS) ${ }^{\dagger}$ and quantifying the $\mathrm{B}_{4} \mathrm{C}$ content with gamma ray spectrometry assuming the water content is known. The time-of-flight transmission measurements results can be used to assess the uniformity of the BoroBond in the RCSB. The data from both measurements will be stored for future comparisons to initial measurements. These methods can be implemented at the RCSB production site, or subsequently at the Y-12 National Security Complex during the operating lifetime of the RCSBs at the Highly Enriched Uranium Materials Facility.

\section{INTRODUCTION}

BoroBond ${ }^{\mathrm{TM}}$, which is a ceramic material containing natural boron carbide $\left(\mathrm{B}_{4} \mathrm{C}\right.$, a neutron absorber) and water (a neutron attenuator), is the filler material of the Rackable Can Storage Boxes (RCSBs) that will store highly enriched uranium in cans at the Highly Enriched Uranium Materials Facility (HEUMF). Both attenuation and absorption are essential for criticality safety of the fissile material stored in RCSBs. This BoroBond ${ }^{\mathrm{TM}}$ material has not yet been used for storage of highly enriched uranium (HEU). To characterize the neutron attenuation and neutron absorption properties of this material, ORNL has performed an extensive series of measurements (over 900) which included: fast neutron and gamma time-of-flight transmission utilizing the Nuclear Materials Identification System (NMIS), thermal and epithermal neutron counting with ${ }^{3} \mathrm{He}$ proportional counters, and activation analysis with gamma ray spectrometry using a high purity germanium (HPGe) detector. These measurements were performed for a series of $12 \times 12$-in square blocks of thickness varying from 2 to 12 inches, with natural $\mathrm{B}_{4} \mathrm{C}$ contents of approximately $0,2.3,4.6$, and $9 \mathrm{wt} \%$, and varying water contents achieved

\footnotetext{
* This work was supported by the Highly Enriched Uranium Materials Facility (HEUMF) project at the Y-12 National Security Complex.

$\dagger$ The time-of-flight transmission measurements utilized the Nuclear Materials Identification System (NMIS) with ${ }^{252} \mathrm{Cf}$ source. NMIS is the system for confirmation of receipts and inventories at HEUMF.

${ }^{*}$ BoroBond $^{\mathrm{TM}}$ is a product of Eagle-Picher Technologies, LLC.
} 
by baking the blocks to remove approximately $5 / 6$ of the water. These measurements were also performed with a special mockup of the RCSB of BoroBond ${ }^{\mathrm{TM}}$ material with $\sim 4.6 \%$ natural $\mathrm{B}_{4} \mathrm{C}$. All three methods used $\mathrm{Cf}-252$ sources.

This report does not describe these measurements in any detail, but presents a method of verifying and quantifying the $\mathrm{B}_{4} \mathrm{C}$ and hydrogen content of the RCSBs at the factory, upon receipt at $\mathrm{Y}-12$, and at any time later while in use at the HEUMF. The data from these measurements can be used to assess the uniformity of the BoroBond in the RCSB and be stored for future comparisons. The details of these measurements are given in ORNL/TM-2002/254. ${ }^{\S}$

\section{DISCUSSION OF THE METHODS}

Unfortunately, no single method investigated could quantify both the hydrogen and $\mathrm{B}_{4} \mathrm{C}$ contents independently. The fast neutron time-of-flight transmission method is sensitive to the water content and not to the $\mathrm{B}_{4} \mathrm{C}$ content. Fast neutron transmission can be used to determine the water content. This is the standard NMIS method that is in use at Y-12 for inventory of canned weapons components. Thermal and epithermal neutron counting with ${ }^{3} \mathrm{He}$ proportional counters and gamma ray spectrometry are both sensitive to both the water and $\mathrm{B}_{4} \mathrm{C}$ content. Gamma ray spectrometry directly measures the gamma ray produced when a neutron is absorbed by boron. Without water present to slow the neutrons down, the boron capture rate is greatly reduced. With any significant amount of $\mathrm{B}_{4} \mathrm{C}$ present the capture gamma rays produced in hydrogen were not significantly observable.

Since ${ }^{3} \mathrm{He}$ proportional counters mainly detect thermal neutrons, these measurements are also sensitive to water and $\mathrm{B}_{4} \mathrm{C}$ content. The thermal and epithermal neutron counting measurement detect neutrons that have not been captured by boron.

What this means for both gamma ray spectrometry and thermal neutron counting is that there are different combinations of water and $\mathrm{B}_{4} \mathrm{C}$ content that yield the same measured result. However, if the water content is known from the fast neutron time-offlight measurements, the $\mathrm{B}_{4} \mathrm{C}$ content can be obtained by the other methods.

\section{RECOMMENDATION}

The recommended method to quantify the water content of the RCSBs is the fast neutron time-of-flight transmission method. Knowing the water content, the $\mathrm{B}_{4} \mathrm{C}$ content will be obtained from the gamma ray spectrometry method, which is preferred over thermal neutron counting because it measures the gamma rays produced in boron capture. The fast neutron time-of-flight transmission and gamma ray spectrometry methods would be implemented as follows. The data will also be used to assess the uniformity of the BoroBond in the RCSB and archived for future comparisons.

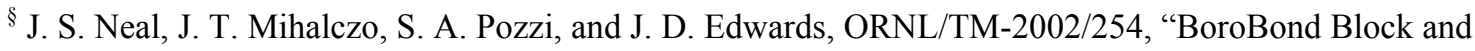
RCSB Measurements For Quantifying Water and $\mathrm{B}_{4} \mathrm{C}$ Content."
} 


\section{FAST NEUTRON TIME-OF-FLIGHT TRANSMISSION}

This method uses two ${ }^{252} \mathrm{Cf}$ sources in ionization chambers inserted in two specially provided 6-in.-deep holes, each equidistant from four fissile storage can locations in the RCSB. Each fissile storage can location would contain one of six fast plastic scintillation detectors connected by cables to the associated electronics. A sketch of this configuration looking down on the RCSB is given in Fig.1. A photograph of a measurement with the special mockup of the RCSB is given in Fig. 2 with only one Cf source in the left source hole (A) and a single detector in one fissile can storage location (1). (In the actual verification measurements the RCSB would not be standing on its side, but the bottom of the RCSB will be $3 \mathrm{ft}$. above the floor to minimize floor reflection effects.) The symmetry of the source detector arrangement allows easy assessment of the uniformity of the BoroBond ${ }^{\mathrm{TM}}$ material in the RCSB.

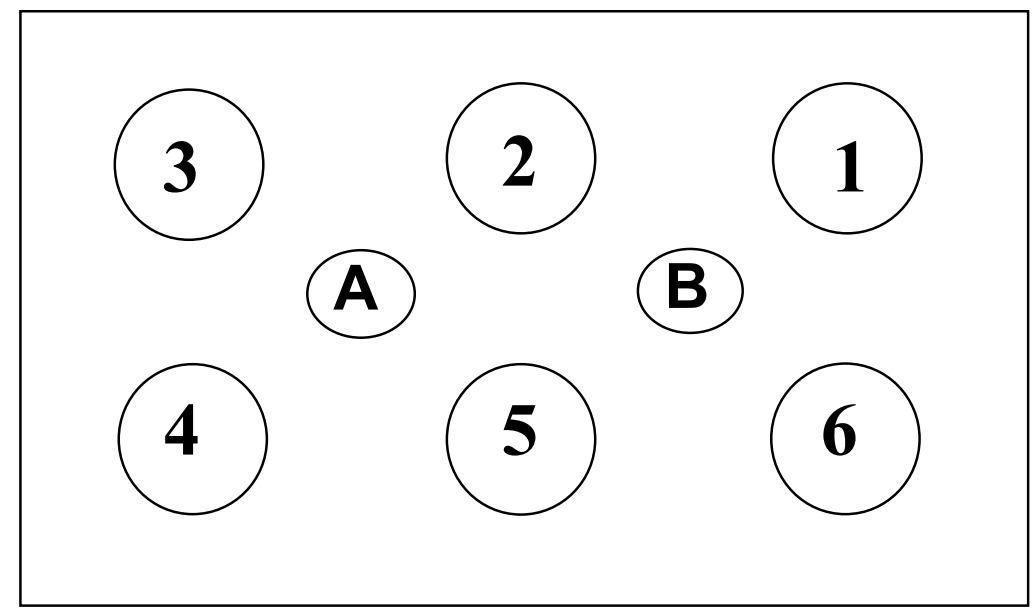

Fig. 1. Sketch of RCSB, top view (source locations A\&B, fissile storage locations 1-6). 


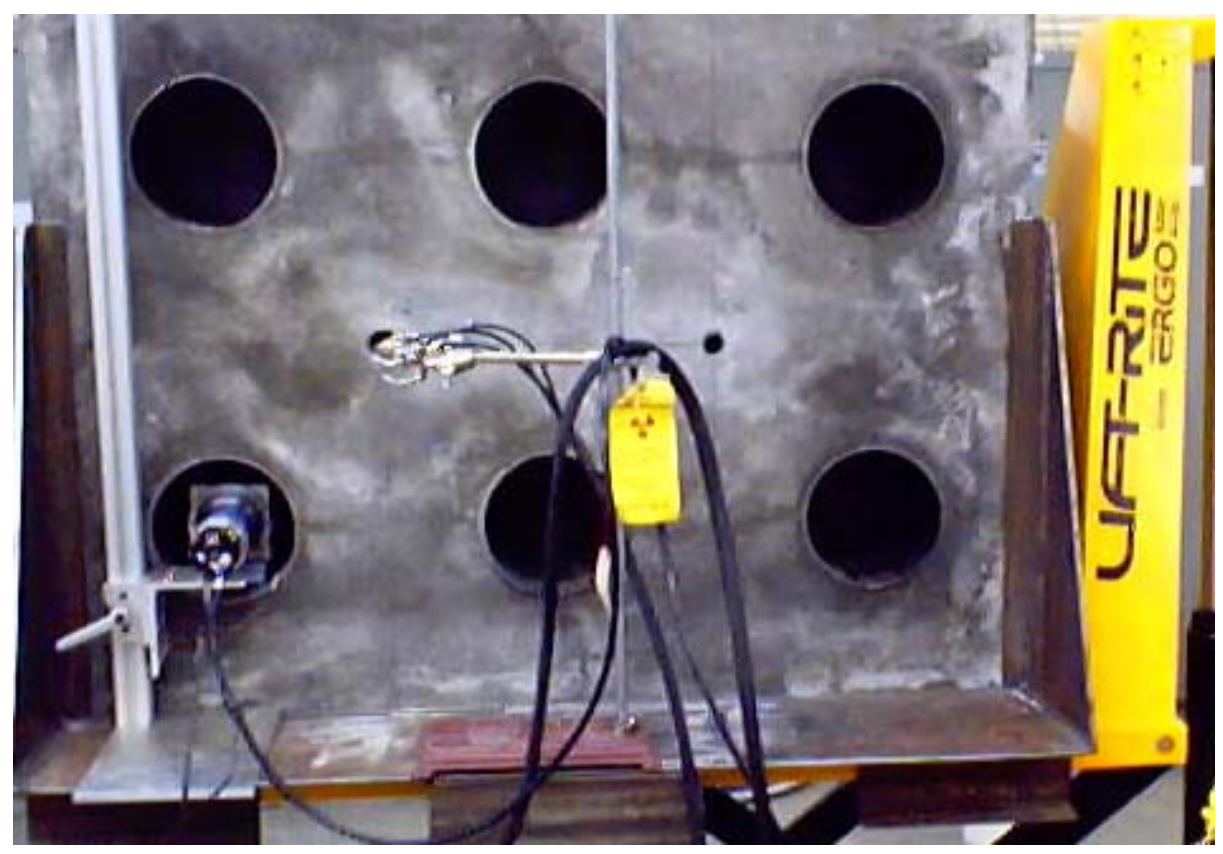

\section{Fig. 2. Photograph of RCSB mockup, with source in hole A on left and detector in fissile storage location 4.}

The ${ }^{252} \mathrm{Cf}$ source initial mass would be 0.5 micrograms (total dose of about 1 $\mathrm{mrem} / \mathrm{hr}$ at one meter) and result in a measurement time of 15 minutes. These two sources would not have to be replaced for the at-the-factory determinations of water content of the RCSBs, because after three years the source intensity is decreased slightly more than a factor of two. Since the RCSB is an excellent neutron shielding material, the sources and detectors for this hydrogen content determination could be stored in a RCSB especially for this purpose.

\section{GAMMA RAY SPECTROMETRY}

Although the exploratory studies at ORNL used a HPGe gamma ray detector (with liquid nitrogen cooling) with high energy resolution, it is recommended that a lower resolution $\mathrm{NaI}$ (cheaper and room temperature) gamma ray detector be used for the atthe-factory measurements. Further evaluations should be performed to confirm this capability for $\mathrm{NaI}$. A sketch of the recommended configuration for gamma ray spectrometry is given in Fig. 3. A 4-in. rectangular block of tungsten alloy between the source and the detector is required to reduce the direct response of the detector to the source. So as to not have to correct for the decay of the source, it is recommended to use an AmBe source (about 400 year half life) that could later be used at Y-12 if desirable (use of this source will have to be verified before implementation). With the water content determined from the fast neutron transmission, gamma ray spectrometry can be used to quantify the $\mathrm{B}_{4} \mathrm{C}$ content. 


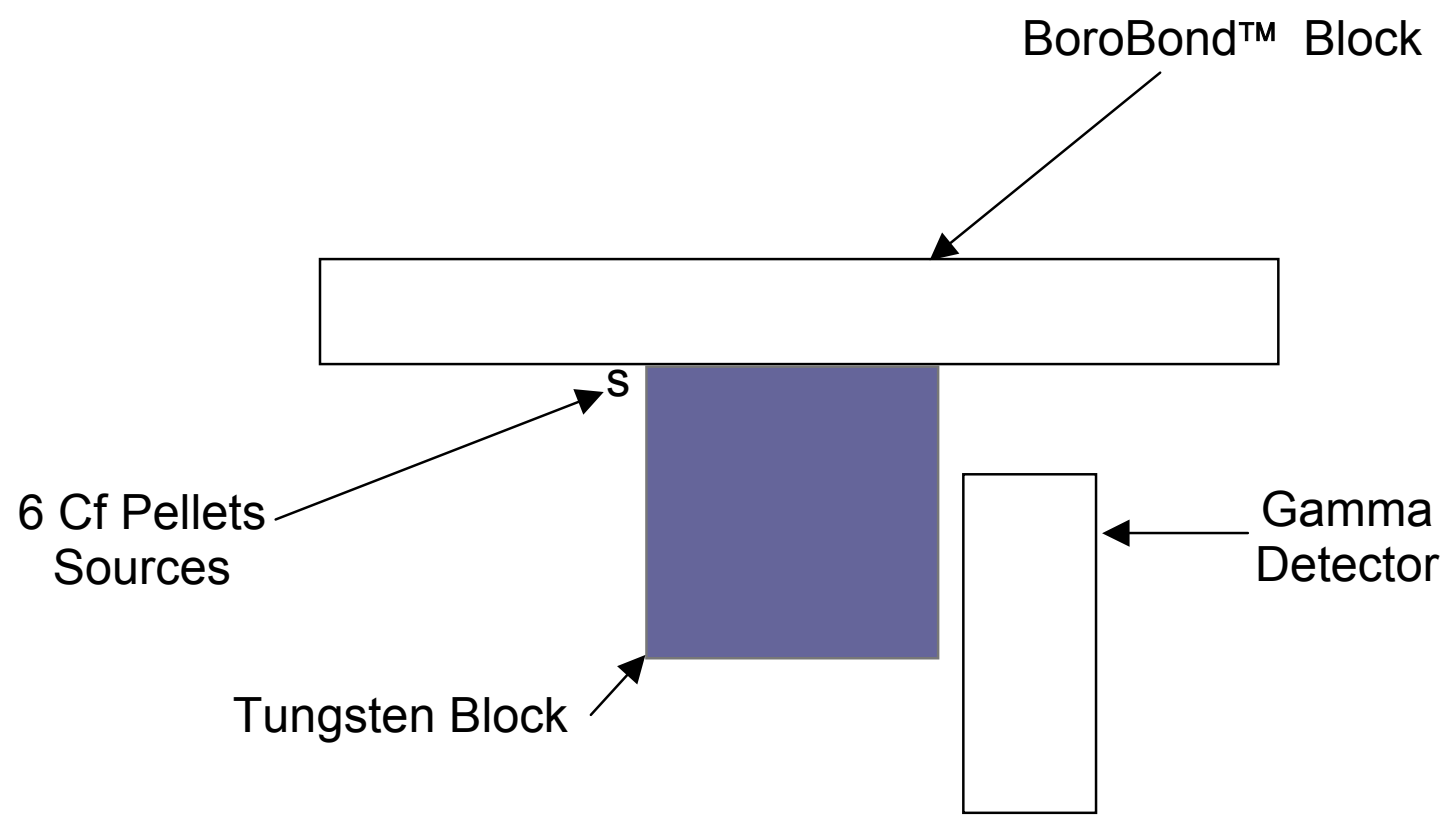

Fig. 3. Sketch of measurement configuration for gamma ray spectroscopy measurements for blocks. (Top View)

\section{STEPS IN AT-THE-FACTORY VERIFICATION OF RCSBs}

This section briefly describes the steps in the at-the-factory-measurement. This is not intended to be a QA procedure for at-the-factory measurements. This QA procedure will have to be jointly drafted by Y-12 and Eagle-Picher with input from ORNL. The following are the basic steps in the procedure and assumes an apparatus exists for holding the 2 sources and 6 detectors for the fast neutron time-of-flight transmission measurement and that the sources and detectors are stored on this fixture in a RCSB for that purpose. It assumes that the gamma ray spectrometry measurement equipment is on a rollup cart that can place the equipment adjacent to the RCSB. It also assumes that the front neutron shield of the source can be rotated upward and back exposing the neutron source, tungsten block, and gamma detector so that they can be placed adjacent the RCSB. It also assumes that a user-friendly system exists with automated analysis so that it could be operated by a non-technical person.

\section{Steps in the RCSB Verification Procedure for RCSBs}

1. Turn on the computer system and operator hits start (this action turns on all power supplies to their nominal values). The computer responds when this is complete.

2. After the operator has allowed the system to warm up for four hours, he initiates the set up of detection system electronics.

3. The software adjusts $\mathrm{Cf}$ source channel electronics to proper values and then instructs the operator to raise the apparatus with the sources and detectors three feet above the storage pallet. The computer then makes the final adjustments of the electronics using the NMIS processor. 
4. The computer then prompts the operator to install the sources and detectors into the $\mathrm{RCSB}$ to be verified. The operator enters the identifying number of the RCSB when this is done.

5. The computer starts the verification of the water content.

6. After completion (15 minutes), the water content is displayed on the terminal screen. An assessment of the uniformity of the BoroBond in the RCSB is also displayed on the terminal screen. All data is stored with the RCSB identifying number. The computer prompts the operator to return the apparatus with the sources and detectors to storage and to prepare for the gamma ray spectrometry measurement.

7. The operator rotates the front of the neutron shield upward and back exposing the neutron source, ${ }^{* *}$ tungsten alloy block, and $\mathrm{NaI}$ detector of the gamma ray spectrometry system which is on a movable cart.

8 The computer instructs the operator to position the system adjacent to one end of the RCSB and locks the cart in place.

9. After positioning the operator prompts the computer to start the measurement.

10 When measurement is finished (20 minutes), computer prompts the operator to position the system at the other end of the RCSB and start another measurement.

11. After 20 minutes of data acquisition, the computer processes both sets of data knowing the water content from Step 6, and prints the weight percent $\mathrm{B}_{4} \mathrm{C}$ from each measurement and the average.

12. The computer then displays a red or green indicator on the screen (green if $w t \% \mathrm{~B}_{4} \mathrm{C}$ above or equal $4 \%$ ), stores data and the result appropriately, and prompts the operator to remove the gamma ray spectrometry equipment.

13. If no more RCSBs are to be measured, the operator instructs the computer to turn the measurement system off. Otherwise, return to Step 4 for measurement of the next RCSB.

\section{CONCLUSIONS}

Extensive measurements at the Oak Ridge National Laboratory (ORNL) with BoroBond ${ }^{\mathrm{TM}}$ blocks of varying thickness, natural boron carbide $\left(\mathrm{B}_{4} \mathrm{C}\right)$ content, and water content, and with a simplified mockup of the Rackable Can Storage Box (RCSB) of fixed natural $\mathrm{B}_{4} \mathrm{C}$ and water content, have led to a method of quantifying the water content of RCSBs by fast neutron time-of-flight transmission measurements (NMIS) (†† $^{\dagger \dagger}$ and quantifying the $\mathrm{B}_{4} \mathrm{C}$ content with gamma ray spectrometry assuming the water content is known. The time-of-flight transmission measurements results can be used to assess the uniformity of the BoroBond in the RCSB. The data from both measurements will be stored for future comparisons to initial measurements. These methods can be implemented at the RCSB production site, or subsequently at the Y-12 National Security Complex during the operating lifetime of the RCSBs at the Highly Enriched Uranium Materials Facility.

\footnotetext{
** It is proposed to use a long half life AmBe neutron source, and this will have to be evaluated experimentally.

$\dagger$ The time-of-flight transmission measurements utilized the Nuclear Materials Identification System

(NMIS) with ${ }^{252} \mathrm{Cf}$ source. NMIS is the system for confirmation of receipts and inventories at HEUMF.
} 


\section{DISTRIBUTION}

BWXT-Y-12

N. J. Antonas

R. B. Barber (2)

K. J. Carroll

M. Conger

S. O. Cox (5)

C. P. Hall

S. S. Hughes

A. C. Kelley

A. W. Krass (10)

R. J. Kroon (10)

T. R. Miller

C. A. Pickett

R. B. Rettberg

D. A. Tollefson

Y-12 Plant Records

Oak Ridge National Laboratory

D. F. Craig

D. J. Hill

J. T. Mihalczo (10)

J. A. Mullens

J. S. Neal

S. A. Pozzi

J. D. White

ORNL Laboratory Records 